\title{
The comparison of efficacy and complications of coblation and radiofrequency thermocoagulation for V2/ V3 idiopathic trigeminal neuralgia: a retrospective cohort study of 292 cases
}

\author{
Chenhui Wang ${ }^{1}$, Zhi Dou', Mengwei Yan², Yuanzhang Tang ${ }^{1}$, Rui Zhao ${ }^{1}$, Yujie Han ${ }^{1}$ and Jiaxiang Ni ${ }^{1 *}$ (D)
}

\begin{abstract}
Background: Coblation is a novel technique in respect of treating idiopathic trigeminal neuralgia. We aimed to identify the efficacy and complications between radiofrequency thermocoagulation (RFT) and coblation for V2N3 idiopathic trigeminal neuralgia (ITN) and investigate the risk factors associated with postoperative facial numbness. Methods: We retrospectively reviewed our cohort of 292 patients who had undergone RFT or coblation for V2N3 ITN. The characteristics of the baseline were collected before surgery. Pain scores, the degree of facial numbness and other complications were evaluated at discharge and 1 month, 3 months, 6 months and 12 months after surgery.
\end{abstract}

Results: Postoperative pain intensity was apparently alleviated in both groups. The initial and 12-months remission rates were 94.0 and $75.3 \%$ in coblation group compared with 96.9 and $78.4 \%$ in RFT group $(P=0.462, P=0.585)$.

The degree of postoperative facial numbness tended to be more severe in RFT group at discharge, 1 month, 6 months and 12 months $(P=0.006, P=0.026, P=0.004, P=0.003)$. Factors significantly associated with more severe facial numbness were procedure of RFT (OR $=0.46,95 \% \mathrm{Cl}: 0.28-0.76, P=0.002)$, history of previous RFT at the affected side $(\mathrm{OR}=2.33,95 \% \mathrm{Cl}: 1.21-4.48, P=0.011)$, and ITN with concomitant continuous pain $(\mathrm{OR}=0.36,95 \% \mathrm{Cl}$ : $0.18-0.71, P=0.004)$.

Conclusion: Coblation could reduce the degree of postoperative facial numbness for ITN, and the efficacy was no less effective than RFT. History of previous RFT at the affected side, procedure of RFT, ITN with concomitant continuous pain was identified as significant factors of the development of postoperative facial numbness.

Keywords: Trigeminal neuralgia, Radiofrequency thermocoagulation, Coblation

\footnotetext{
*Correspondence: nijiaxiang123@163.com

${ }^{1}$ Department of Pain Management, Xuanwu Hospital, Capital Medical University, No.45 Changchun Street, Xicheng District, Beijing 100053, China

Full list of author information is available at the end of the article
} changes were made. The images or other third party material in this article are included in the article's Creative Commons licence, unless indicated otherwise in a credit line to the material. If material is not included in the article's Creative Commons licence and your intended use is not permitted by statutory regulation or exceeds the permitted use, you will need to obtain permission directly from the copyright holder. To view a copy of this licence, visit http://creativecommons.org/licenses/by/4.0/ The Creative Commons Public Domain Dedication waiver (http://creativecommons.org/publicdomain/zero/1.0/) applies to the data made available in this article, unless otherwise stated in a credit line to the data. 


\section{Background}

Trigeminal neuralgia (TN) is one of the most common types of neuropathic pain in the orofacial region. The annual morbidity of TN is approximately 5-28.6/100, 000 [1-3], which is relatively higher among the elderly. It is a chronic pain syndrome characterized by recurrent paroxysmal, lightning-like, or acupuncture-like pain in the facial distribution along regions of trigeminal nerve [4]. However, the etiology and pathogenesis of TN have not been clearly defined at present. Initial treatment is generally based on a pharmacological approach. But lots of patients do not respond to drugs and also cannot endure the side effects of drug tolerance, such as nausea, vomiting, and dizziness $[5,6]$. For these reasons, neurosurgery treatments, such as micro-vascular decompression [7] (MVD), Gasserian ganglion percutaneous techniques [8, 9], and stereotactic radiosurgery [10], need to be considered to relieve the pain. However, people are more likely to accept minimally invasive treatment like radiofrequency thermocoagulation (RFT), which has been widely used in the elderly who suffer from facial pain of trigeminal neuralgia, rather than the surgery that requires craniotomy and tracheal intubation. Although the remission rate of RFT is satisfactory at a 1-year follow-up, the recurrence rate of RFT ranges from 15 to $46 \%$ [11, 12] during long-term follow-up, with a multitude of patients complained about the facial numbness after RFT. Coblation is a novel technique, which was widely used in intraoperative tissue cutting of otolaryngology [13] and other fields. It depends on the plasma field of sodium ions generated by plasma knife head and normal saline, which can result in molecular dissociation $[14,15]$, rather than thermal damage. Currently, coblation has been reported in the treatment of thoracic neuralgia [16] and idiopathic trigeminal neuralgia $[17,18]$, while our previous small sample study and short-term follow-up results suggested that the analgesic effect of the coblation group at 3 months was better than that of the RFT group, and the incidence of facial numbness was even less in coblation group [19]. However, some issues of coblation about changes in facial numbness, the degree of numbness compared with patients after RFT, and the risk factors associated with the degree of numbness have not been cleared in our previous study. Therefore, our study aims to investigate longterm outcomes of efficacy and complications of coblation for V2/V3 ITN and to estimate risk factors associated with the degree of postoperative facial numbness.

\section{Methods}

\section{Study design and patients}

In this retrospective study, we identified all patients who underwent RFT or coblation for treatment of TN between August 2017 and April 2019 in the department of pain management at Xuanwu Hospital of Capital Medical University in China. Data collection and analysis was also approved by Institutional Review Board (IRB) of Xuanwu hospital. Written informed consent from patients was obtained before follow-up entry.

The inclusion criteria were as follows: (1) ITN of maxillary and/or mandibular divisions in accordance with the International Classification of Headache Disorders [20], (2) no space occupying lesions, (3) poor effect of drug therapy or side effects were intolerable.

The following patients were excluded: (1) patients with severe systemic diseases who were intolerable to surgery and anesthesia, (2) coagulation dysfunction or local infection in the puncture area before surgery, (3) patients with mental illness, who were unable to express subjective feelings clearly.

Clinical data of patients were extracted from the electronic medical records. All the patients who had undergone RFT or coblation for ITN were followed as the routine practice. The follow-up data were registered in the hospital data system. Each patient was taken physical examination to assess pain, numbness and other complications at discharge (3 days after surgery). Long term follow-up was carried out at 1 month, 3 months, 6 months and 12 months by telephone interview by specially trained investigators on schedule. Although telephone interview carries risks of bias including the characteristics of the respondent and the examiner, it was acceptable for patients who were unable to come to our center for further examination.

\section{Grouping}

The patients were grouped according to the procedures they selected after an informed comprehensive discussion with their surgeon: RFT group and coblation group. All procedures were performed in an operating room under fluoroscopic guidance of C-arm.

\section{RFT group}

Vital signs were monitored in operating room. The patient was lying in supine position with the head keeping overhanging. After the visualization of foramen ovale (FO) by $\mathrm{C}$-arm, the patients underwent a sterile preparation and local anesthesia. Then a 22-G puncture needle $(15 \mathrm{~cm}$, with a $5-\mathrm{mm}$ active tip; Cosman TICC5 electrode, Cosman Medical, Burlington, MA, U.S.A.) was advanced into the FO using the Hartel anterior approach. $\mathrm{C}$-arm was then performed to confirm the location of the needle tip and the tip was adjusted according to patients' reactions to the sensory $(50 \mathrm{~Hz}, 1 \mathrm{~ms})$ and motor $(2 \mathrm{~Hz}, 0.1 \mathrm{~ms})$ stimulation test until paresthesia was elicited in the affected area. After positioning was accomplished satisfactorily, patients were administered 
intravenous anesthesia (propofol $1.5-2 \mathrm{mg} / \mathrm{kg}$ ). Thermocoagulation was performed at $70{ }^{\circ} \mathrm{C}$ for $180 \mathrm{~s}$.

\section{Coblation group}

The procedures before verifying the position of the needle tip were the same as the RFT group. When the needle was located in FO, we connected the anode of the neuro-stimulator (B. Braun Co., Ltd., Melsungen, Germany) to the tail of coblation needle (DXR-G1100A185; Xi'an Surgical Medical Technology Co., Ltd., Xi'an, China) and the cathode was connected with patient's skin. We turned on the neuro-stimulator and adjusted it to $2 \mathrm{~Hz}$ and $0.1 \mathrm{~ms}$, and gradually increased the intensity of the stimulus until it caused reproducible pain at $0.5 \mathrm{mV}$. When reproducible pain was successfully repeated, intravenous anesthesia was applied (propofol $1.5-2 \mathrm{mg} / \mathrm{kg}$ ). The ablation energy and the coagulation energy of low-temperature plasma multifunction operating system (SM-D380C; Xi'an Surgical Medical Technology Co., Ltd., Xi'an, China) was level 1 and parameters were unchanged during the operation. The ablation time was $30 \mathrm{~s}$, and the ablation was performed again after 30 s.

\section{Clinical materials}

Clinical characteristics of patients were collected from electronic medical records, including gender, age, disease duration, affected side (left, right), co-morbidity (diabetes mellitus or not), baseline pain numeric rating scale (NRS) scores $(0=$ no pain, $10=$ severe pain $)$, pain characteristics (paroxysmal, continuous), pain distribution in anatomic trigeminal nerve dermatome $(\mathrm{V} 2, \mathrm{~V} 3, \mathrm{~V} 2+$ V3), and history of previous treatment at the affected side (none, MVD, RFT, other).

All patients were followed up by telephone interviews at 1-month, 3-months, 6 -months and 12-months by our investigators respectively. Follow-up data included NRS scores of pain intensity, pain relief, the degree of postoperative facial numbness, recovery from postoperative facial numbness and other complications.

Pain intensity was assessed using NRS score $(0=$ no pain, $10=$ severe pain). Pain relief was considered when the NRS score was less than 4 . For facial numbness, the degree of facial numbness was assessed by the Barrow Neurological Institute (BNI) facial hypesthesia scale [21]: Class I: no facial numbness; Class II: mild facial numbness and not bothersome; Class III: facial numbness and somewhat bothersome; Class IV: facial numbness and very bothersome. With regard to postoperative facial numbness, we observed three outcomes at the endpoint of our study: (1) no numbness: patients without subjective facial numbness; (2) remission: the degree of facial numbness was improved by 1-2 BNI level but still hadn't reached BNI I; (3) no remission: postoperative facial numbness was not changed or even raised some levels. Besides, none of the patients had subjective facial numbness before surgery and all the patients had stopped taking medicines before surgery. Other complications such as oral ulcer, corneal hypoesthesia, masticatory weakness, hypoesthesia of temperature and tinnitus were recorded as well.

\section{Statistical analysis}

Under normal distribution and equality of variances, quantitative data were reported as means \pm standard deviation (SD) and were compared using the independentsample $t$ test or the paired-sample $t$ test. Otherwise, non-normal variables were reported in the median with interquartile range (IQR) and Wilcoxon rank-sum test was used. Categorical data were described by frequencies and proportions and were compared by Pearson's chisquare test or the Wilcoxon rank-sum test.

Univariate and multivariate ordered logistic regression analysis was used to assess the statistical significance of the potential variables in patients' clinical characteristics, with previous parallel lines test (likelihood ratio test). Each relevant parameter was calculated with an associated confidence interval (CI) and odds ratios (ORs) respectively.

Statistical analyses were performed using SPSS software, version 23.0 (IBM SPSS, New York, NY, USA). The level of significance was set at $P<0.05$ (2-tailed).

\section{Results}

\section{Characteristics of the patients}

A total of 292 patients underwent RFT or Coblation procedure; however, 25 patients in RFT group and 20 patients in coblation group were lost to follow-up. Eventually, we obtained complete follow-up data of 247 cases, including 97 patients in RFT group and 150 patients in coblation group.

The baseline characteristics of the patients are summarized in Table 1 . There were no statistically significant differences in age, sex, affected side, the distribution of pain, disease duration, pain characteristics, co-morbidity, history of previous treatment at affected side and preoperative NRS scores between 2 groups.

\section{Efficacy}

We started our postoperative follow-up at discharge (3 days after surgery). NRS scores were significantly lower in both groups at discharge compared with pre-surgery (RFT: $t=37.194, P<0.001$; Coblation: $t=44.949, P<$ 0.001). There had been no cases of anesthesia dolorosa at discharge. There was no significant difference in the mean NRS scores between the two groups at discharge, 1-month, 3-months, 6-months and 12-months of follow- 
Table 1 Demographic characteristics of patients

\begin{tabular}{|c|c|c|c|}
\hline Variables & RFT $(n=97)$ & Coblation $(n=150)$ & $P$ \\
\hline Age $($ mean $\pm S D)(y)$ & $63.51 \pm 11.46$ & $61.07 \pm 10.44$ & 0.086 \\
\hline Sex, n (\%) & & & 0.716 \\
\hline Male & $34(35.1 \%)$ & $56(37.3 \%)$ & \\
\hline Female & $63(64.9 \%)$ & $94(62.7 \%)$ & \\
\hline Affected side, $\mathrm{n}(\%)$ & & & 0.055 \\
\hline Left & 29 (29.9\%) & $63(42 \%)$ & \\
\hline Right & $68(70.1 \%)$ & 87 (58\%) & \\
\hline Distribution of pain, n(\%) & & & 0.065 \\
\hline V2 & $24(24.7 \%)$ & $30(20 \%)$ & \\
\hline V3 & $18(18.6 \%)$ & $48(32 \%)$ & \\
\hline $\mathrm{V} 2+\mathrm{V} 3$ & $55(56.7 \%)$ & $72(48 \%)$ & \\
\hline Disease duration (mean $\pm \mathrm{SD}$ ) (mo) & $64.75 \pm 64.98$ & $66.87 \pm 75.09$ & 0.820 \\
\hline Pain characteristics, n(\%) & & & 0.846 \\
\hline Paroxysmal & $83(85.6 \%)$ & $127(84.7 \%)$ & \\
\hline Continuous & $14(14.4 \%)$ & $23(15.3 \%)$ & \\
\hline Co-morbidity, n(\%) & & & 0.432 \\
\hline Diabetes mellitus & $8(8.2 \%)$ & $17(11.3 \%)$ & \\
\hline No diabetes mellitus & $89(91.8 \%)$ & $133(88.7 \%)$ & \\
\hline History of previous treatment at the affected side, $n(\%)$ & & & 0.499 \\
\hline Previous RFT & $18(18.6 \%)$ & $25(16.7 \%)$ & \\
\hline Previous MVD & $8(8.2 \%)$ & $6(4 \%)$ & \\
\hline Other & $4(4.1 \%)$ & $8(5.3 \%)$ & \\
\hline None & $67(69.1 \%)$ & $111(74 \%)$ & \\
\hline
\end{tabular}

up $(P>0.05)$. Postoperative pain intensity is shown in Table 2.

When the postoperative NRS score was < 4, pain relief was considered. At discharge, the remission rate (pain relief) was $96.9 \%$ (94/97) in RFT group, whereas it was 94.0\% (141/150) in coblation group (correction for continuity of $\left.X^{2}=0.540, P=0.462\right)$. At 1 month after surgery, the remission rate was $90.7 \%$ (88/97) in RFT group and $89.3 \%(134 / 150)$ in coblation group $\left(X^{2}=0.125, P=\right.$ $0.724)$. At 3 months after surgery, the remission rate was $86.6 \%(84 / 97)$ in RFT group and $84.0 \%(126 / 150)$ in coblation group $\left(X^{2}=0.312, P=0.576\right)$. At 6 months after surgery, the remission rate was $85.6 \%$ (83/97) in RFT group and $82.0 \%(123 / 150)$ in coblation group $\left(\chi^{2}=\right.$ $0.541, P=0.462)$. At 12 months after surgery, the remission rate was $78.4 \%(76 / 97)$ in RFT group and $75.3 \%$ $(113 / 150)$ in coblation group $\left(\chi^{2}=0.298, P=0.585\right)$.

\section{Complications}

Facial numbness on the affected side was the most frequent complication after surgery. The incidence of postoperative facial numbness in the RFT group at discharge was $91.8 \%$ (89/97), and the proportions of each grade were: BNI I 8.2\% (8/97), BNI II 23.7\% (23/97), BNI III

Table 2 Different time of NRS scores between 2 groups

\begin{tabular}{|c|c|c|c|c|c|}
\hline NRS score (mean \pm SD) & $\mathrm{RFT}(n=97)$ & Coblation $(n=150)$ & $t$ & $95 \% \mathrm{Cl}$ of the Difference & $P$ \\
\hline Baseline & $7.65 \pm 1.35$ & $7.72 \pm 1.31$ & -0.407 & $-0.414-0.270$ & 0.684 \\
\hline Discharge & $1.23 \pm 1.10$ & $1.17 \pm 1.27$ & 0.383 & $-0.249-0.369$ & 0.702 \\
\hline 1 month & $0.96 \pm 1.77$ & $0.93 \pm 1.84$ & 0.108 & $-0.440-0.491$ & 0.914 \\
\hline 3 months & $1.12 \pm 1.99$ & $1.23 \pm 2.15$ & -0.379 & $-0.638-0.433$ & 0.705 \\
\hline 6 months & $1.19 \pm 2.11$ & $1.42 \pm 2.30$ & -0.808 & $-0.806-0.337$ & 0.420 \\
\hline 12 months & $1.58 \pm 2.51$ & $1.71 \pm 2.45$ & -0.401 & $-0.765-0.506$ & 0.689 \\
\hline
\end{tabular}

NRS score is considered as quantitative data and independent-sample $t$ test is used to assess it $\mathrm{Cl}$ Confidence interval 
60.8\% (59/97), BNI IV 7.2\% (7/97). However, 88\% (132/ 150 ) of the patients in coblation group had postoperative facial numbness at discharge, and the proportions of each grade were: BNI I 12\% (18/150), BNI II 36\% (54/ 150), BNI III 50.7\% (76/150), BNI IV 1.3\% (2/150). At the end point of our follow up, we found that in RFT group, the degree of postoperative facial numbness was alleviated in $36.1 \%$ of the patients (35/97), 19.5\% (19/97) patients had no subjectively facial numbness and $44.3 \%$ (43/97) patients remained unalleviated. In coblation group, postoperative facial numbness was gradually alleviated in $25.3 \%$ of the patients (38/150), 34.7\% (52/150) patients had no subjectively facial numbness and $40 \%$ $(60 / 150)$ patients remained unalleviated. In addition, the proportions of the two groups were: RFT group: BNI I 19.6\% (19/97), BNI II 43.3\% (42/97), BNI III 35.1\% (32/ 97) BNI IV 2.1\% (2/97); Coblation group: BNI I $34.7 \%$ (52/150), BNI II 42.7\% (64/150), BNI III 21.3\% (32/150), BNI IV 1.3\% (2/150). Complications after different procedures are recorded in Tables 3 and 5. Changes in facial numbness after surgery are presented in Table 4 .

According to the results showed in Tables 3, 4 and 5, there was a significant difference between two groups in the degree of facial numbness except for 3-months and the mean-rank of two groups suggested the degree of postoperative facial numbness tended to more severe in RFT group. However, there was no significant difference in the prognosis of facial numbness between the two groups although some advantage was showed in the rate of "no numbness" in coblation group.

Other complications such as oral ulcer, masticatory weakness, corneal hypoesthesia, hypoesthesia of temperature and tinnitus were not significantly different between 2 groups $(P>0.05)$.

\section{Risk factors associated with postoperative facial numbness for ITN}

The degree of numbness (BNI I, BNI II, BNI III-IV) was taken as the dependent variable. As a small proportion of BNI IV could not ensure the accuracy of the model, we combined it with BNI III into BNI III-IV, representing moderate or severe postoperative facial numbness. Firstly, we performed a univariate ordered logistic regression analysis between the outcomes and each independent variable of patients' characteristics. Variables with $P<0.05$ were likely to entered subsequent multivariate analysis. Subsequently, we constructed a multivariate ordered logistic regression model using the enter procedure among the potential candidate variables. Variables were examined for multicollinearity before entering regression model and there was no multicollinearity between the independent variables.

Table 6 presents the potential variables related to the degree of postoperative facial numbness, and the results of univariate analysis. Based on the results of univariate analysis, four of the variables (disease duration, pain characteristic, history of previous treatment at the affected side, procedure) were considered to be candidate variables. These variables were then used for multivariate ordered logistic regression analysis. Factors significantly associated with more severe facial numbness were procedure of RFT $(\mathrm{OR}=0.46,95 \% \mathrm{CI}: 0.28-0.76, P=$ $0.002)$, history of previous RFT at the affected side $(\mathrm{OR}=$ 2.33, 95\%CI: $1.21-4.48, P=0.011)$, and ITN with concomitant continuous pain (OR $=0.36,95 \% \mathrm{CI}$ : $0.18-0.71$, $P=0.004)$, which was presented in Table 7 .

\section{Discussion}

Coblation is a relatively novel technique applied in neuropathic pain. Some previous studies found [19] that the coblation group had lower postoperative NRS scores than RFT group and the risk of postoperative numbness in patients with V1, V2, and V3 ITN was reduced. However, the previous studies were limited to small sample sizes and short-term follow up. Besides, because of the specificity of V1, some studies indicated that the appropriate temperature of RFT for the treatment of V1 ITN was lower than V2/V3 ITN [22, 23], which was to avoid complications such as diplopia and keratitis. To prevent the influences of different temperatures on the evaluation of surgical outcomes, we only included V2/V3 ITN in the present study with a 12-months follow-up.

In terms of the efficacy of coblation, the postoperative NRS scores at discharge were significantly lower than before surgery and it continuously remained at a low level during our 12-months follow up, which was identical with RFT group in respect of postoperative analgesic effect. Compared with the initial remission rate of $96.9 \%$

Table 3 Complications except for facial numbness after surgery

\begin{tabular}{|c|c|c|c|c|}
\hline Variables & RFT & Coblation & $x^{2}$ & $P$ \\
\hline Oral ulcer, n(\%) & $5(5.2 \%)$ & $10(6.7 \%)$ & 0.236 & 0.627 \\
\hline Masticatory weakness, n(\%) & $23(23.7 \%)$ & $40(26.7 \%)$ & 0.271 & 0.603 \\
\hline Corneal hypoesthesia, n(\%) & $21(21.6 \%)$ & $36(24 \%)$ & 0.183 & 0.669 \\
\hline Hypoesthesia of temperature, n(\%) & $30(30.9 \%)$ & $51(34 \%)$ & 0.252 & 0.615 \\
\hline Tinnitus, n(\%) & $14(14.4 \%)$ & $26(17.3 \%)$ & 0.365 & 0.546 \\
\hline
\end{tabular}

Complication is considered as categorical data and Pearson's chi-square test is used to assess it 
Table 4 The recovery state from postoperative facial numbness at 12 months

\begin{tabular}{llllll}
\hline & No numbness, $\mathbf{n}(\%)$ & Remission, $\mathbf{n}(\%)$ & No remission, $\mathbf{n}(\%)$ & $\mathbf{Z}$ & $\mathbf{P}$ \\
\hline RFT $(n=97)$ & $19(19.5 \%)$ & $35(36.1 \%)$ & $43(44.3 \%)$ & 2.828 \\
Coblation $(n=150)$ & $52(34.7 \%)$ & $38(25.3 \%)$ & $60(40.0 \%)$ & \\
\hline
\end{tabular}

The recovery state is considered as ranked data and nonparametric test (Independent-Samples Kruskal-Wallis Test) is applied to assess it

in RFT group, it was 94\% in coblation group, which was consistent with the result of a previous study ranging from 85.3 to $97.7 \%$ [19]. At the endpoint of follow up, the remission rate was 75.3 and $78.4 \%$, respectively in coblation group and RFT group. Despite the slightly lower remission rate in coblation group, there was no statistically significant difference. Some literature review reported that the remission rate after RFT [22, 24] ranged from 50.4 to $80.7 \%$ in a follow-up of 5 years. However, as a relatively novel technique for the treatment of ITN, it was difficult to perform the long-term results according to the available and limited clinical data. Therefore, a big-sample of long-term follow-up study is still required to illustrate the efficacy of coblation.

Concerning postoperative complications, postoperative facial numbness had been the most disturbing issue among patients who accepted minimally invasive treatment of ITN. In contrast to the remission rate, the coblation group had some advantages in the degree of postoperative facial numbness compared with the RFT group. Our study results indicated that the degree of postoperative facial numbness tended to increase in RFT group, mainly due to the different mechanisms of the two techniques. Coblation $[14,15]$ is a unique modality that uses bipolar radiofrequency energy to ablate and coagulate soft tissue at low temperatures $\left(40{ }^{\circ} \mathrm{C}-70^{\circ} \mathrm{C}\right)$ with minimal thermal damage to surrounding tissues. During coblation, conductive saline solution is converted in the gap between the needle tip and the tissue and it is excited into an ionized plasma layer. Once the plasma layer meets the tissue, intercellular bonds would be destroyed by the ions. However, the mechanism of RFT is thermal damage as $\mathrm{A} \delta$ and C-type nerve fibers for pain transmission would be coagulated and denatured by temperatures of $\leq 80^{\circ} \mathrm{C}$, but $\mathrm{A} \alpha$ and $\mathrm{A} \beta$ nerve fibers $[25,26]$ would not be affected. Yao [22, 23] and Tang [9] had investigated the eligible temperature of RFT for V2/ V3 ITN and the recommended temperature was 68$75^{\circ} \mathrm{C}$, which could reduce the incidence of postoperative facial numbness, but the temperature was still relatively high compared with coblation. Neither of the two procedures could selectively destroy C-type nerve fibers. But thermal damage to the nerves is minimized by coblation, which attributes to $40^{\circ} \mathrm{C}-70^{\circ} \mathrm{C}$ operating temperatures. This may be explanations of the fact that lower degree of postoperative facial numbness occurred in coblation group rather than RFT group. For the non-significant outcome of numbness at 3 months, the possible reason might be information bias existed in this study - the follow-up data might be influenced by different mood of the examiner and possible suggestibility of the examiner. Other complications such as oral ulcer, masticatory weakness, corneal hypoesthesia, hypoesthesia of temperature and tinnitus were no significant differences between the 2 groups.

Compared with the preferred $70^{\circ} \mathrm{C}$ 60s RFT with 2 $\mathrm{mm}$ active tips, we adopted $70^{\circ} \mathrm{C} 180 \mathrm{~s}$ RFT with $5 \mathrm{~mm}$ active tips in our center because good pain relief, less recurrence rate and less complications can be obtained under this kind of condition, based on published literature $[22,23]$. Theoretically, ablation temperature, ablation time and radius of active tips have impact on numbness. However, in terms of most studies about

Table 5 The postoperative facial numbness (BNI I-IV) in follow up

\begin{tabular}{|c|c|c|c|c|c|c|c|c|c|c|}
\hline & \multicolumn{2}{|l|}{ Discharge } & \multicolumn{2}{|l|}{1 month } & \multicolumn{2}{|l|}{3 months } & \multicolumn{2}{|l|}{6 months } & \multicolumn{2}{|l|}{12 months } \\
\hline & $\begin{array}{l}\text { RFT } \\
(n=97)\end{array}$ & $\begin{array}{l}\text { Coblation } \\
(n=150)\end{array}$ & $\begin{array}{l}\text { RFT } \\
(n=97)\end{array}$ & $\begin{array}{l}\text { Coblation } \\
(n=150)\end{array}$ & $\begin{array}{l}\text { RFT } \\
(n=97)\end{array}$ & $\begin{array}{l}\text { Coblation } \\
(n=150)\end{array}$ & $\begin{array}{l}\text { RFT } \\
(n=97)\end{array}$ & $\begin{array}{l}\text { Coblation } \\
(n=150)\end{array}$ & $\begin{array}{l}\text { RFT } \\
(n=97)\end{array}$ & $\begin{array}{l}\text { Coblation } \\
(n=150)\end{array}$ \\
\hline $\mathrm{I}, \mathrm{n}(\%)$ & $8(8.2 \%)$ & $18(12 \%)$ & 9 (9.3\%) & $20(13.3 \%)$ & $12(12.4 \%)$ & 29 (19.3\%) & $15(15.5 \%)$ & 40 (26.7\%) & 19 (19.6\%) & $52(34.7 \%)$ \\
\hline II, n (\%) & $23(23.7 \%)$ & $54(36 \%)$ & 25 (25.8\%) & $54(36 \%)$ & 34 (35.1\%) & 59 (39.3\%) & 41 (42.3\%) & 71 (47.3\%) & 42 (43.3\%) & 64 (42.7\%) \\
\hline III, n (\%) & 59 (60.8\%) & 76 (50.7\%) & 59 (60.8\%) & 73 (48.7\%) & 48 (49.5\%) & 59 (39.3\%) & 38 (39.2\%) & 37 (24.7\%) & 32 (35.1\%) & $32(21.3 \%)$ \\
\hline IV, n (\%) & 7 (7.2\%) & $2(1.3 \%)$ & $4(4.1 \%)$ & $3(2.0 \%)$ & $3(3.1 \%)$ & $3(2.0 \%)$ & 3 (3.1\%) & $2(1.3 \%)$ & 2 (2.1\%) & $2(1.3 \%)$ \\
\hline Mean-Rank & 138.07 & 114.9 & 135.38 & 116.64 & 134.04 & 117.51 & 139.35 & 114.08 & 139.80 & 113.78 \\
\hline Median & III & III & III & III & III & $\|$ & $\|$ & $\|$ & $\|$ & $\|$ \\
\hline Wilcoxon W & $17,235.0$ & & $17,496.5$ & & $17,626.5$ & & $17,111.5$ & & $17,067.0$ & \\
\hline P & $0.006^{*}$ & & $0.026^{*}$ & & 0.056 & & $0.004^{*}$ & & $0.003^{*}$ & \\
\hline
\end{tabular}

$\mathrm{BNI}$ is considered as ranked data and Wilcoxon rank-sum test was used to assess it

${ }^{*} P<0.05$ 
Table 6 Univariate ordered logistic regression analysis for the factors associated with the degree of postoperative numbness at 12 months

\begin{tabular}{|c|c|c|c|c|c|c|c|}
\hline Variables & BNI I & BNI II & BNI III-IV & LR-test & $P$ & OR & $\begin{array}{l}\text { 95\% Confidence } \\
\text { Interval }\end{array}$ \\
\hline Age (years) (mean \pm SD) & $61.7 \pm 13.1$ & $61.5 \pm 10.4$ & $63.1 \pm 9.1$ & 0.47 & 0.416 & 1.01 & $0.99-1.03$ \\
\hline Sex, n (\%) & & & & 0.52 & & & \\
\hline Male & $23(25.6 \%)$ & $41(45.6 \%)$ & $26(28.9 \%)$ & & 0.558 & 1.15 & $0.71-1.59$ \\
\hline Female & $48(30.6 \%)$ & $65(41.4 \%)$ & $44(28.0 \%)$ & & & & \\
\hline Affected side, n (\%) & & & & 0.68 & & & \\
\hline Right & 44 (28.4\%) & 65 (41.9\%) & $46(29.7 \%)$ & & 0.649 & 0.89 & $0.55-1.46$ \\
\hline Left & $27(29.3 \%)$ & $41(44.6 \%)$ & $24(26.1 \%)$ & & & & \\
\hline Distribution of pain, n (\%) & & & & 0.59 & & & \\
\hline V2 & $17(31.5 \%)$ & $26(48.1 \%)$ & $11(20.4 \%)$ & & & & \\
\hline V3 & $22(33.3 \%)$ & $26(39.4 \%)$ & $18(27.3 \%)$ & & 0.745 & 1.12 & $0.57-2.18$ \\
\hline$V_{2}+V_{3}$ & $32(25.2 \%)$ & $54(42.5 \%)$ & $41(32.3 \%)$ & & 0.147 & 1.55 & $0.86-2.11$ \\
\hline Disease duration (months) (mean \pm SD) & $58.1 \pm 66.4$ & $61.8 \pm 60.0$ & $80.5 \pm 89.2$ & 0.56 & $0.048^{*}$ & 1.00 & $1.00-1.01$ \\
\hline Pain characteristic & & & & 0.46 & & & \\
\hline Paroxysmal & $65(31.0 \%)$ & $94(44.8 \%)$ & $51(24.3 \%)$ & & $0.001^{*}$ & 0.33 & $0.17-0.65$ \\
\hline Continuous & $6(16.2 \%)$ & $12(32.4 \%)$ & $19(51.4 \%)$ & & & & \\
\hline Co-morbidity, n (\%) & & & & 0.76 & & & \\
\hline Diabetes mellitus & $8(32 \%)$ & $10(40 \%)$ & $7(28 \%)$ & & 0.798 & 0.90 & $0.42-1.95$ \\
\hline No diabetes mellitus & $63(28.4 \%)$ & $96(43.2 \%)$ & $63(28.4 \%)$ & & & & \\
\hline History of previous procedure at the affected side, n (\%) & & & & 0.46 & & & \\
\hline Previous RFT & $9(20.9 \%)$ & $13(30.2 \%)$ & $21(48.8 \%)$ & & $0.002^{*}$ & 2.79 & $1.47-5.26$ \\
\hline Previous MVD & $2(14.3 \%)$ & $7(50 \%)$ & $5(35.7 \%)$ & & 0.137 & 2.17 & $0.78-6.02$ \\
\hline Other & $2(16.7 \%)$ & $5(41.7 \%)$ & $5(41.7 \%)$ & & 0.112 & 2.44 & $0.81-7.34$ \\
\hline None & $58(32.6 \%)$ & $81(45.5 \%)$ & 39 (21.9\%) & & & & \\
\hline Treatment, n (\%) & & & & 0.81 & & & \\
\hline RFT & 19 (19.6\%) & $42(43.3 \%)$ & $36(37.1 \%)$ & & & & \\
\hline Coblation & $52(34.7 \%)$ & $64(42.7 \%)$ & $34(22.7 \%)$ & & $0.003^{*}$ & 0.48 & $0.30-0.78$ \\
\hline Baseline NRS score (mean \pm SD) & $7.68 \pm 1.36$ & $7.81 \pm 1.32$ & $7.53 \pm 1.29$ & 0.22 & 0.513 & 0.94 & $0.79-1.12$ \\
\hline NRS score at discharge (mean \pm SD) & $1.15 \pm 1.01$ & $1.08 \pm 1.07$ & $1.39 \pm 1.53$ & 0.28 & 0.235 & 1.12 & $0.93-1.36$ \\
\hline
\end{tabular}

$L R$ test Likelihood ratio test, $O R$ Odds ratio

${ }^{*} P<0.05$

RFT $\left(70{ }^{\circ} \mathrm{C} 180 \mathrm{~s}\right.$ with $5 \mathrm{~mm}$ active tips) for ITN and our study, RFT procedures have much numbness than coblation.

In addition, complications are also important aspects in evaluating the effectiveness of treatment and improving the satisfaction of patients. However, due to the mechanism of treatment, postoperative facial numbness was almost inevitable among patients who accepted minimally invasive treatment. To explore the risk factors of the degree of postoperative facial numbness in ITN patients, we conducted a multivariate analysis and the results showed that the pain characteristics, previous treatment at the affected side, and procedure were risk factors significantly associated with the degree of postoperative facial numbness. The continuous pain [27, 28] was described as dull, aching, burning and other different from the sharp-like. Some studies reported [27] that the prognosis of continuous ITN patients was less effective than paroxysmal ITN patients, with $80 \%$ initial remission rate and 54\% 5-years remission rate. However, we also observed more severe postoperative facial numbness in patients with continuous ITN in our study, which might be explained by the central sensitization hypothesis [29]. The hypotheses rated that the intense, repetitive and sustained stimulus could increase the membrane excitability and synaptic efficacy, and decrease the thresholds of activation. The chronic and continuous stimulus to trigeminal nerve would lead to pain hypersensitivity, that is, innocuous stimulation could be considered as pain-causing noxious stimulation. We 
Table 7 Ordered logistic regression analysis results for variables by the enter procedure

\begin{tabular}{|c|c|c|c|c|}
\hline Variables & LR-test & $P$ & OR & 95\% Confidence Interval \\
\hline Disease duration (months) (mean \pm SD) & 0.755 & 0.188 & 1.00 & $0.99-1.01$ \\
\hline \multicolumn{5}{|l|}{ Pain characteristic } \\
\hline Paroxysmal & & $0.004^{*}$ & 0.36 & $0.18-0.71$ \\
\hline \multicolumn{5}{|l|}{ Continuous } \\
\hline \multicolumn{5}{|l|}{ History of previous neurosurgery, n (\%) } \\
\hline Previous RFT & & $0.011^{*}$ & 2.33 & $1.21-4.48$ \\
\hline Previous MVD & & 0.526 & 1.41 & $0.49-4.11$ \\
\hline Other & & 0.181 & 2.16 & $0.70-6.48$ \\
\hline \multicolumn{5}{|l|}{ None } \\
\hline \multicolumn{5}{|l|}{ Treatment, n (\%) } \\
\hline \multicolumn{5}{|l|}{ RFT } \\
\hline Coblation & & $0.002^{*}$ & 0.46 & $0.28-0.76$ \\
\hline
\end{tabular}

Test of Parallel Lines (LR test, Chi-Square $=3.415, P=0.755$ )

$L R$ test Likelihood ratio test, $O R$ Odds ratio

${ }^{*} P<0.05$

speculated that the pain hypersensitivity caused by pathophysiological changes in pain pathway would also affect the superficial sensation, which would be the possible cause of the severe postoperative facial numbness. In addition, some scholars also rated [28] that the continuous pain was transformed from paroxysmal pain over time if left untreated, and the changes involved the development of sensory impairment. But it is just supposition; evidence is needed to support the speculation.

Meanwhile, we also found that patients with recurrent ITN, who had accepted RFT, suffered more severe facial numbness compared with primary ITN patients. The destruction of the Gasserian ganglion by neurosurgeries would result in denaturation and necrosis of partial trigeminal nerve, and the damaged nerve fibers would be gradually repaired physiologically, which may lead to the recurrence of ITN [30]. And we supposed that the second damage to the repaired nerves would result in severe facial numbness, compared with those who accepted primary destructive neurosurgeries. But more researches are needed to support our supposition.

There are still some limitations about our study. First, patients with V1 ITN were excluded because of the appropriate ablation temperature differed from V2/V3 ITN. Second, it was a retrospective study and selection bias could not be avoided. Large-scale, randomized, double-blind studies will be needed to validate our findings in the future.

\section{Conclusion}

Coblation is an effective treatment for V2/V3 ITN. It could reduce the degree of postoperative facial numbness for ITN, and the efficacy is no less effective than
RFT. History of previous RFT at the affected side, procedure of RFT, ITN with concomitant continuous pain was identified as significant factors of the development of postoperative facial numbness. These findings would be considered to improve the satisfaction of patients after surgery during our clinical work.

\section{Abbreviations \\ RFT: Radiofrequency thermocoagulation; ITN: Idiopathic trigeminal neuralgia; TN: Trigeminal neuralgia; MVD: Micro-vascular decompression; IRB: Institutional review board; FO: Foramen ovale; NRS: Numerical rating scale; BNI: Barrow neurological institute; SD: Standard deviation; IQR: Interquartile range; Cl: Confidence interval; OR: Odds ratio}

\section{Acknowledgements \\ Not applicable.}

\section{Authors' contributions}

All authors have read and approved the manuscript. CHW helped design the study, conduct study, analyze data, and prepare the article. CHW, RZ and YJH helped collect data. ZD, YZT, MWY and JXN helped revise the article. CHW and ZD contributed equally to the work and should be regarded as co-first authors.

\section{Funding}

This study was supported by Beijing Municipal Administration of Hospitals Incubating Program (PX2020033), which provide financial support for the design and conduct of the research, interpretation of data, and preparation of the article.

\section{Availability of data and materials}

The datasets used and analyzed during the current study are available from the corresponding author on reasonable request.

\section{Ethics approval and consent to participate}

Ethical approval for this retrospective study (XW20190125) was provided by the Institutional Review Board of Xuanwu Hospital, Capital Medical

University. Before follow-up entry, all participants signed an informed con-

sent for data collection and information use.

Consent for publication

Not applicable. 


\section{Competing interests}

The authors have no conflicts of interest to declare.

\section{Author details}

'Department of Pain Management, Xuanwu Hospital, Capital Medical University, No.45 Changchun Street, Xicheng District, Beijing 100053, China.

${ }^{2}$ Capital Medical University, Fengtai District, Beijing 100069, China.

Received: 14 May 2020 Accepted: 20 December 2020

Published online: 07 January 2021

\section{References}

1. Hall GC, Carroll D, Parry D, McQuay HJ. Epidemiology and treatment of neuropathic pain: the UK primary care perspective. Pain. 2006;122:156-62.

2. Koopman JS, Dieleman JP, Huygen FJ, de Mos M, Martin CG, Sturkenboom MC. Incidence of facial pain in the general population. Pain. 2009;147:122-7.

3. Katusic S, Beard CM, Bergstralh E, Kurland LT. Incidence and clinical features of trigeminal neuralgia, Rochester, Minnesota, 1945-1984. Ann Neurol. 1990; 27:89-95.

4. Gronseth G, Cruccu G, Alksne J, Argoff C, Brainin M, Burchiel K, et al. Practice parameter: the diagnostic evaluation and treatment of trigeminal neuralgia (an evidence-based review): report of the Quality Standards Subcommittee of the American Academy of Neurology and the European Federation of Neurological Societies. Neurology. 2008;71:1183-90.

5. Zakrzewska JM, Patsalos PN. Long-term cohort study comparing medical (oxcarbazepine) and surgical management of intractable trigeminal neuralgia. Pain. 2002;95:259-66

6. Shaikh S, Yaacob HB, Abd RR. Lamotrigine for trigeminal neuralgia: efficacy and safety in comparison with carbamazepine. J Chin Med Assoc. 2011;74: 243-9.

7. Ko AL, Ozpinar A, Lee A, Raslan AM, McCartney S, Burchiel KJ. Long-term efficacy and safety of internal neurolysis for trigeminal neuralgia without neurovascular compression. J Neurosurg. 2015;122:1048-57.

8. Jin HS, Shin JY, Kim YC, Lee SC, Choi EJ, Lee PB, et al. Predictive factors associated with success and failure for radiofrequency thermocoagulation in patients with trigeminal neuralgia. Pain Physician. 2015;18:537-45.

9. Tang $Y Z$, Wu BS, Yang LQ, Yue JN, He LL, Li N, et al. The long-term effective rate of different branches of idiopathic trigeminal neuralgia after single radiofrequency thermocoagulation: a cohort study. Medicine (Baltimore). 2015;94:e1994

10. Regis J, Tuleasca C, Resseguier N, Carron R, Donnet A, Gaudart J, et al. Long-term safety and efficacy of Gamma Knife surgery in classical trigeminal neuralgia: a 497-patient historical cohort study. J Neurosurg. 2016;124:1079-87.

11. Liu P, Zhong W, Liao C, Yang M, Zhang W. The role of percutaneous radiofrequency thermocoagulation for persistent or recurrent trigeminal neuralgia after surgery. J Craniofac Surg. 2016;27:e752-5.

12. Ran B, Wei J, Zhong Q, Fu M, Yang J, Chen X, et al. Long-term follow-up of patients treated with percutaneous radiofrequency thermocoagulation via the foramen rotundum for isolated maxillary nerve idiopathic trigeminal neuralgia. Pain Med. 2019;20:1370-8.

13. Roje Z, Racic G, Dogas Z, Pisac VP, Timms M. Postoperative morbidity and histopathologic characteristics of tonsillar tissue following coblation tonsillectomy in children: a prospective randomized single-blind study. Coll Antropol. 2009;33:293-8.

14. Chang KW. Randomized controlled trial of coblation versus electrocautery tonsillectomy. Otolaryngol Head Neck Surg. 2005;132:273-80.

15. D'Eredita R, Bozzola L. Molecular resonance vs. coblation tonsillectomy in children. Laryngoscope. 2009;119:1897-901.

16. Yang LQ, Gong WY, Wang XP, Dou Z, Zeng YJ, Ni JX. Computed tomography-guided percutaneously controlled ablation of the thoracic paravertebral nerve due to thoracic neuropathic pain. Pain Pract. 2017;17: 792-9.

17. Rui Z, Chenhui W, Xiaoping W, Yuanzhang T, Qi W, Liqiang Y, et al. Different modes CT-guided low temperature plasma ablation for treating middleaged and elderly trigeminal neuralgia. Chin J Intervent Imaging Ther. 2019; 16:713-6.

18. Haili HE, Liqiang $Y$, Liangliang HE, Jiaxiang NI, Shengwen S. Clinical effect of trigeminal ganglion low temperature plasma ablation in the treatment of the third branches lesion of idiopathic trigeminal neuralgia. China Med Herald. 2018;15:107-10.
19. Li Y, Guo Y, Yang L, Ni J. Comparison of the short-term outcomes after lowtemperature plasma radiofrequency ablation (coblation) in the Gasserian ganglion for the treatment of idiopathic trigeminal neuralgia. J Pain Res. 2019;12:1235-42.

20. Headache Classification Committee of the International Headache Society (IHS). The international classification of headache disorders, 3rd edition. Cephalalgia. 2018;38:1-211.

21. Rogers CL, Shetter AG, Ponce FA, Fiedler JA, Smith KA, Speiser BL. Gamma knife radiosurgery for trigeminal neuralgia associated with multiple sclerosis. J Neurosurg. 2002;97:529-32.

22. Yao $\mathrm{P}$, Hong T, Wang ZB, Ma JM, Zhu YQ, Li HX, et al. Treatment of bilateral idiopathic trigeminal neuralgia by radiofrequency thermocoagulation at different temperatures. Medicine (Baltimore). 2016;95:e4274

23. Yao P, Deng YY, Hong T, Wang ZB, Ma JM, Zhu YQ, et al. Radiofrequency thermocoagulation for V2N3 idiopathic trigeminal neuralgia: effect of treatment temperatures on long-term clinical outcomes: a cohort study. Medicine (Baltimore). 2016;95:e4019.

24. Zheng S, Li X, Li R, Yang L, He L, Cao G, et al. Factors associated with longterm risk of recurrence after percutaneous radiofrequency thermocoagulation of the Gasserian ganglion for patients with trigeminal neuralgia: a multicenter retrospective analysis. Clin J Pain. 2019;35:958-66.

25. Sweet $\mathrm{WH}$, Wepsic JG. Controlled thermocoagulation of trigeminal ganglion and rootlets for differential destruction of pain fibers. 1. Trigeminal neuralgia. J Neurosurg. 1974;40:143-56.

26. Ding Y, Li H, Hong T, Zhu Y, Yao P, Zhou G. Combination of pulsed radiofrequency with continuous radiofrequency thermocoagulation at low temperature improves efficacy and safety in V2/N3 primary trigeminal neuralgia. Pain Physician. 2018;21:E545-53.

27. Brisman R. Typical versus atypical trigeminal neuralgia and other factors that may affect results of neurosurgical treatment. World Neurosurg. 2013;79: 649-50.

28. Li X, Zheng S, Yang L, Cao Z, Ni J, Zhang Y. Factors predicting successful outcomes for percutaneous radiofrequency thermocoagulation in patients with idiopathic trigeminal neuralgia: implications for surgical decision making. Pain Pract. 2019;19:491-9.

29. Hu WH, Zhang K, Zhang JG. Atypical trigeminal neuralgia: a consequence of central sensitization? Med Hypotheses. 2010;75:65-6.

30. Song L, He L, Pei Q, Peng K, Wang N, Guo Z, et al. CT-guided percutaneous radiofrequency thermocoagulation for glossopharyngeal neuralgia: a retrospective clinical study of 117 cases. Clin Neurol Neurosurg. 2019;178: $42-5$.

\section{Publisher's Note}

Springer Nature remains neutral with regard to jurisdictional claims in published maps and institutional affiliations.

Ready to submit your research? Choose BMC and benefit from:

- fast, convenient online submission

- thorough peer review by experienced researchers in your field

- rapid publication on acceptance

- support for research data, including large and complex data types

- gold Open Access which fosters wider collaboration and increased citations

- maximum visibility for your research: over $100 \mathrm{M}$ website views per year

At BMC, research is always in progress.

Learn more biomedcentral.com/submissions 